\title{
A pediatric case of Ortner's syndrome caused by heritable pulmonary arterial hypertension and review of the literature
}

\author{
Özkan Kaya ${ }^{1}$, Tamer Yoldaş ${ }^{1}$, Selmin Karademir ${ }^{1}$, Utku Arman Örün ${ }^{1}$, Eyüp Sarı ${ }^{2}$ \\ Division of ${ }^{1}$ Pediatric Cardiology, ${ }^{2}$ Department of Pediatrics, Dr. Sami Ulus Maternity, Children's Health and Diseases \\ Training and Research Hospital, Ankara, Turkey.E-mail: tameryoldas@gmail.com \\ Received: 7th October 2018, Accepted: 18th February 2019
}

SUMMARY: Kaya Ö, Yoldaş T, Karademir S, Örün UA, Sarı E. A pediatric case of Ortner's syndrome caused by heritable pulmonary arterial hypertension and review of the literature. Turk J Pediatr 2019; 61: 963-966.

An 11-year-old male, who complained of hoarseness and fatigue on effort presented to our institution for evaluation. Left vocal cord paralysis and severe pulmonary hypertension was diagnosed. The patient had an enlarged pulmonary artery due to pulmonary hypertension which was responsible for compression to left vocal cord paralysis causing hoarseness. Ortner's syndrome or cardiovocal syndrome is known as hoarseness due to left vocal cord paralysis secondary to cardiac pathologies. Although hoarseness of voice is frequently encountered in the otorhinolaryngology clinics, pulmonary hypertension related hoarseness is an unusual presentation in childhood.

Key words: Ortner's syndrome, heritable pulmonary arterial hypertension, childhood.

Hoarseness due to left recurrent laryngeal nerve (RLN) paralysis caused by identifiable cardiovascular disease has been described as Ortner's syndrome or cardiovocal syndrome. ${ }^{1-2}$ This syndrome is a rare condition and to our knowledge only 80 patients have been presented in the literature as a thorough research in PubMed showed. Cardiovocal syndrome is common in older age, but can occur in children rarely. There are only seven pediatric cases in the literature. ${ }^{3-6}$ Herein, we reported a child, presented with hoarseness and fatigue on effort who diagnosed Ortner's syndrome due to heritable pulmonary arterial hypertension (HPAH).

\section{Case Report}

An eleven year-old male patient who complained of hoarseness was admitted to the otorhinolaryngology department. Indirect laryngoscopy revealed a paralyzed left vocal fold without evidence of any anatomical lesion. $\mathrm{He}$ was referred to the pediatric cardiology department to evaluate dilated pulmonary artery segment on chest radiography (Fig. 1).The patient complained also of a history of fatigue with effort. On auscultation, the first heart sound and the pulmonary component of the second heart sound were loud. No murmur was detected. The other examinations including lung, musculoskeletal, neurologic, and abdominal systems were normal. The patient had no lymphadenopathy. Electrocardiogram revealed right axis deviation and right ventricular hypertrophy.

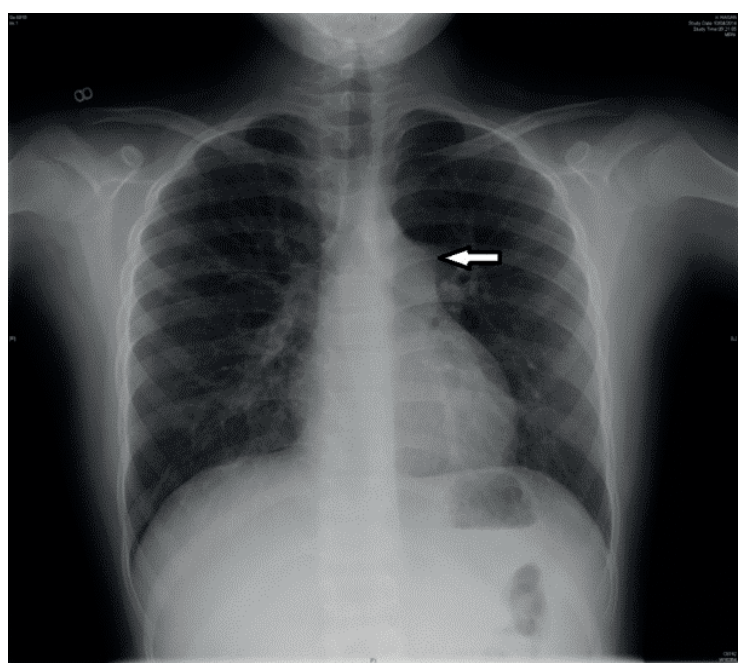

Fig. 1. Chest X-ray showed enlarged pulmonary artery segment (white arrow). 
Echocardiography showed enlarged right heart chambers and pulmonary artery with an estimated RV (right ventricle) systolic pressure of $91 \mathrm{~mm} \mathrm{Hg}$. There was no structural heart disease to explain pulmonary arterial hypertension (PAH). The systemic venous Doppler and abdominal ultrasonography were normal.

On laboratory analyses, complete blood count and coagulation tests were normal. C-reactive protein, erythrocyte sedimentation rate, antinuclear antibodies, anti-ds DNA, anticardiolipin antibodies, CH50 complement, anti-neutrophil cytoplasmic antibody and rheumatoid factor were within normal range. Pro- BNP level was $1561 \mathrm{pg} / \mathrm{ml}$. The sixminute walk test (6MWT) was 260 meters. Functional capacity was class II according to New York Heart Association Classification. ${ }^{7}$

A contrast enhanced computed tomography (CT) of the chest and neck depicted enlarged pulmonary arteries (Fig. 2). High resolution CT (HRCT) showed centrilobular translucent density of lung peripheral area and interlobular septal thickening (Fig. 3). Right heart catheterization revealed right atrium (RA) pressure of $8 \mathrm{~mm} \mathrm{Hg}$, mean pulmonary artery pressure (mPAP) of $91 \mathrm{~mm} \mathrm{Hg}$, pulmonary artery wedge pressure (PAWP) of $14 \mathrm{~mm} \mathrm{Hg}$, pulmonary vascular resistance index (PVRI) of

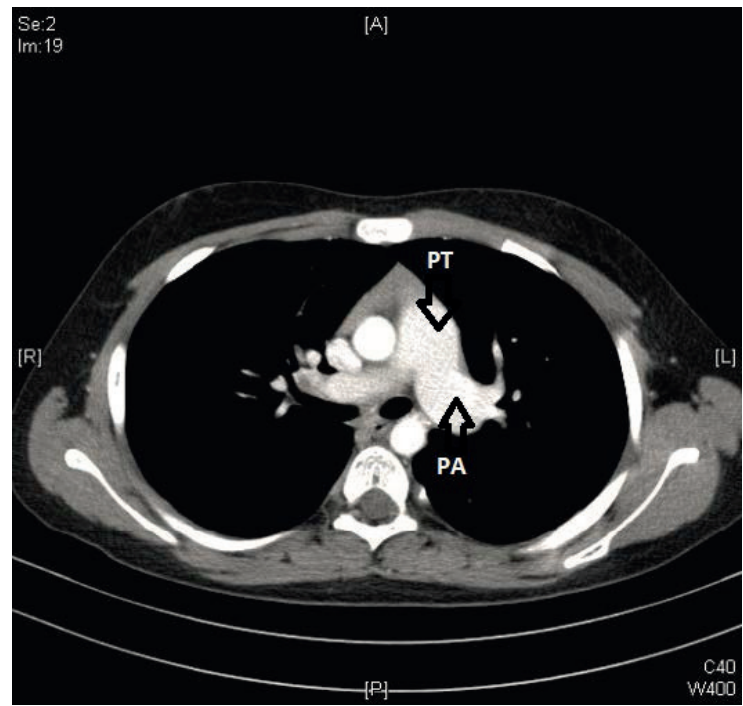

Fig. 2. Thoracic computed tomography signs of pulmonary arterial hypertension, pulmonary trunk (PT, $25 \mathrm{~mm}$ ) and left pulmonary artery (PA, $20 \mathrm{~mm}$ ) dilatation.
28.3 WU/ $/ \mathrm{m}^{2}$, and the ratio of pulmonary and systemic vascular resistance (PVR/ SVR) ratio of 1 . No other structural heart disease was shown in the catheter angiogram. p. $R 491 \mathrm{~W}$ (c.l.471C $>T$ (heterozygous mutation) of bone morphogenetic protein receptor type 2 gene was detected. He was diagnosed as HPAH. The patient was started on $\mathrm{PAH}$-specific therapy and he is on regular follow up .The hoarseness of voice has been resolved completely after 7 months with PAH - specific therapy.

A signed consent was obtained from the parents for publication.

\section{Discussion}

Ortner's syndrome or the cardiovocal syndrome is the name originally given to paralysis of the left vocal cord in cases of mitral stenosis associated with a large left atrium and pulmonary artery dilation. In 1897, Norbert Ortner, Austrian physician described a series of three cases of mitral stenosis suffering from hoarseness of voice because of left recurrent laryngeal nerve palsy. ${ }^{8}$ He deduced that hoarseness was caused by compression of the left recurrent laryngeal nerve by the enlarged left atrium. In 1911, Fetterolf and Norris studied the anatomic relations of left recurrent laryngeal nerve in cadavers and concluded that the nerve must be squeezed

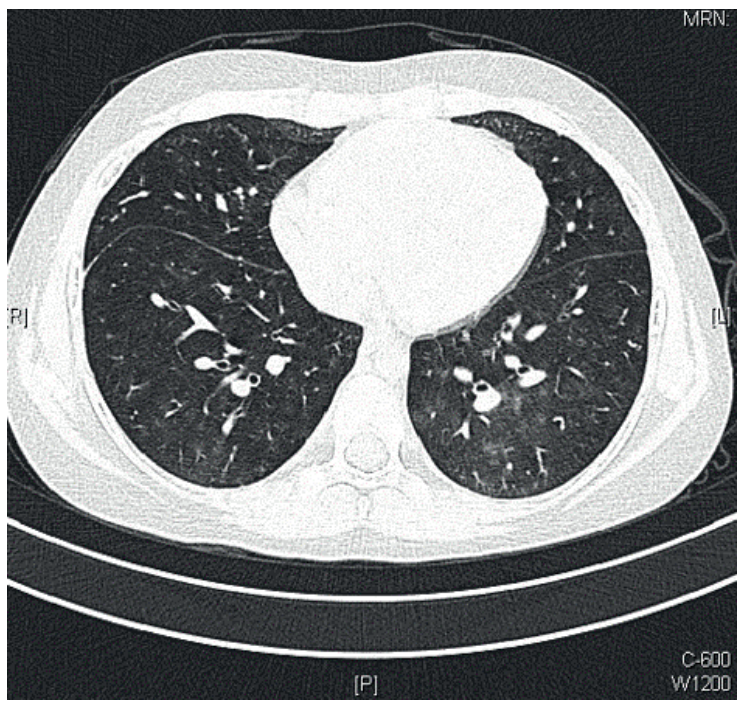

Fig. 3. High resolution computed tomography showed centrilobular translucent density, interlobular septal thickening and patchy frozen glass densities. 
between the left pulmonary artery and the aorta or ligamentum arteriosum. ${ }^{9}$ Since then it has been encountered with other mediastinal structures causing mass effects and in many cardiac disorders; congenital heart diseases, Eisenmenger complex, mitral valve disorders, atrial myxoma, left ventricular and aortic aneurysms, primary pulmonary hypertension, recurrent pulmonary artery embolism, cor pulmonale and in iatrogenic conditions. ${ }^{1,2,10-12}$ It has been suggested that the nerve is compressed between an enlarged dilated pulmonary artery and the aorta.

There are only seven pediatric cases with Ortner's syndrome secondary to structural heart diseases in the literature. Condon et al. ${ }^{3}$ presented two infants with significant underlying congenital heart disease (type 2 aortopulmonary window, ventricular septal defect, patent ductus arteriosus; large ventricular septal defect). After surgical repair of their congenital heart defect, both infants had normal vocal cord function. Robida et al. ${ }^{4}$ described cardiovocal syndrome in an infant with a double outlet of the right ventricle. Zaki et al. ${ }^{5}$ reported three infants, the first patient had non obstructive supracardiac TAPVC (total anomalous pulmonary venous connection), a moderate sized atrial defect, two small mid muscular ventricular septal defect, severe pulmonary hypertension, and severe dilatation of the pulmonary artery. The second patient had mitral atresia, VSD, PDA, ASD, and severe pulmonary hypertension. The third patient had double outlet right ventricle with mitral atresia, ASD and severe pulmonary hypertension. David et al. ${ }^{6}$ reported an infant who had unilateral right pulmonary artery agenesis and congenital cystic adenomatoid malformation of the right lung with Ortner's syndrome. All the seven cases described above had moderate to severe pulmonary hypertension with dilated pulmonary artery. The dilated pulmonary artery caused compression of the left recurrent laryngeal nerve resulting in hoarseness of voice.

Cardiovocal syndrome caused by idiopathic pulmonary artery hypertension and dilated pulmonary trunk has also been described rarely in the literature. ${ }^{1,13-15}$ No structural heart disease that cause PAH were detected with transthoracic echocardiography and conventional angiography in our patient. Also, we ruled out other etiologic causes of pulmonary hypertension such as lung diseases, other diseases that may lead to pulmonary hypertension with multifactorial mechanisms, drugs/toxins and associated PAH causes. In the gene analysis, heterozygote mutation, p.R491W (c.1.471C $>$ T of bone morphogenetic protein receptor type 2 gene was determined. A left vocal cord palsy, as well as HPAH was diagnosed, suggesting that pulmonary artery dilatation associated with HPAH led to left recurrent laryngeal nerve palsy. To the best of our knowledge, there is no pediatric case of cardiovocal syndrome or Ortner's syndrome associated with hereditary PAH in the literature. The hoarseness of our patient has been resolved completely after 7 months with PAH therapy.

Hoarseness is not a common problem in pediatric clinical practice. Trauma, congenital anomaly, vocal cord paralysis, gastro esophageal reflux, mucosal lesion and infection could be the cause of etiologic factors. In cases with constant hoarseness, Ortner syndrome should be kept in mind, cardiac examinations should be performed to evaluate completely. This case suggests that HPAH should be suspected in any case in childhood with unexplained left vocal cord palsy.

\section{REFERENCES}

1. Subramaniam V, Herle A, Mohammed N, Thahir M Ortner's syndrome: case series and literature review. Braz J Otorhinolaryngol 2011; 77: 559-562.

2. Heikkinen J, Milger $\mathrm{K}$, Alejandre-Lafont $\mathrm{E}$, et al. Cardiovocal syndrome (Ortner's syndrome) associated with chronic thromboembolic pulmonary hypertension and giant pulmonary artery aneurysm: Case report and review of the literature. Case Rep Med 2012; 2012: 230736.

3. Condon LM, Katkov H, Singh A, Helseth HK Cardiovocal syndrome in infancy. Pediatrics 1985; 76: 22-25.

4. Robida A, Povhe B. Cardiovocal syndrome in an infant with a double outlet of the right ventricle. Eur J Pediatr 1988; 148: 15-16.

5. Zaki SA, Asif S, Shanbag P. Ortner syndrome in infants. Indian Pediatr 2010; 47: 351-353.

6. David JJ, Mohanlal S, Sankhe P, Ghildiyal Y. Unilateral right pulmonary artery agenesis and congenital cystic adenomatoid malformation of the right lung with Ortner's syndrome. Lung India 2016; 33: 553-555. 
7. Lammers AE, Adatia I, Del Cerro MJ, et al. Functional classification of pulmonary hypertension in children: report from the PVRI Pediatric Taskforce, Panama 2011. Pulm Circ 2011; 1: 280-285.

8. Ortner N. Recurrenslahmung bei mitral stenose. Wien Klin Wochenschr 1897; 10: 753-755.

9. Fetterolf G, Norris GW. The anatomical explanation of the paralysis of the left recurrent laryngeal nerve found in certain cases of mitral stenosis. Am J Med Sci 1911; 141: 625-638.

10. Plastiras SC, Pamboucas C, Zafiriou T, Lazaris N, Toumanidis S. Ortner's syndrome: a multifactorial cardiovocal syndrome. Clin Cardiol 2010; 33: E99-E100.

11. Nakao M, Sawayama T, Samukawa M, et al. Left recurrent laryngeal nerve palsy associated with primary pulmonary hypertension and patent ductus arteriosus. J Am Coll Cardiol 1985; 5: 788-792.
12. Mulpuru SK,Vasavada BC, Punukollu GK, Patel AG Cardiovocal syndrome: a systematic review. Heart Lung Circ 2008; 17: 1-4.

13. Yasui T, Kasamatsu N, Seto T, Shinozuka N, Nakamura A, Hashizume I. A case of Ortner syndrome caused by primary pulmonary hypertension. Nihon Kokyuki Gakkai Zasshi 2006; 44: 823-827.

14. Nakahira M, Nakatani $H$, Takeda T. Left vocal cord paralysis associated with long-standing patent ductus arteriosus. AJNR Am J Neuroradiol 2001; 22: 759 761

15. Paquette CM, Manos DC, Psooy BJ. Unilateral vocal cord paralysis: a review of CT findings, mediastinal causes, and the course of the recurrent laryngeal nerves. Radiographics 2012; 32: 721-740. 